\title{
Partners in Participation: integrated approaches to widening access in higher education
}

\author{
MARK MURPHY \& TED FLEMING
}

\section{Introduction}

Like social inclusion, 'partnership' became part of the preferred policy jargon in the 1990s, both in EU and in national policy arenas. Whilst it could be argued that the usage of such terms reflects a consensus on social and political issues that so far does not exist, the popularity of 'partnership'-based models of social intervention does tend to reflect more recent developments in the ways in which social issues have been tackled. Both in the United Kingdom and the Republic of Ireland, new forms of partnership have been put in place, which have paved the way for different understandings of policy development and political decisionmaking. This emergence of partnership approaches at local, regional and EU level created 'new sets of relationships between elected representatives, officials, trade unions, employers and the community and voluntary sector' (National Economic and Social Forum, 1997), which bear witness to a change in the control and administration of policy initiatives, potentially moving from a top-down to a more decentralised approach.

According to Skilbeck (2001), the challenge of the partnership approach to higher education is 'clear', and while this can also be debated, given the sector's historical autonomy and the differential impact of policy on HE institutions, a challenge can be witnessed in the widening participation policy agenda. At both a national and institutional level, in terms of the broad field of access provision, an increasing emphasis has been placed on 'getting out' to potential students in order to widen participation. As the most recent set of initiatives in this area, outreach programmes embody a different set of agendas compared to more 'traditional' initiatives such as Summer schools and one-year Access courses for adults. Importance is placed on facilitating the ability of the institution to 'fit' into the needs of the wider society, rather than the other way round. Whether in relation to schools, communities or employers, such programmes tend to be more pro-active in their efforts to widen participation. For instance, work-based access initiatives are viewed as an effective means of providing entry routes to sections of the population unable to take advantage of higher education, and involve the linking of academic credit to student/employer-negotiated projects.

Creating new demand is a key aspect of these kinds of efforts to widen participation, as their focus is on encouraging those who would not otherwise consider $\mathrm{HE}$ an option for them. As a result, they particularly target people from social classes IIIM-V, social groups at the centre of both Scottish and Irish government 
policy in widening participation to HE. Another study on access and higher education in the North-East of England identifies this as a key element of any major attempt to widen participation.

One of the recurring themes ... has been the importance of getting people to think that $\mathrm{HE}$ is for them. For a large number of people higher education is simply not on their agenda. This is even before they start to worry about student loans or coping with writing essays. If they [universities] want to widen participation, then working to change attitudes to higher education is a critical area (Baxter \& Hunt, 1999, p. 36).

Detailed in this article are two case studies carried out over the last two years in the UK and Ireland which embody the objectives of tackling social exclusion and widening access to education via a partnership and integrated approach. One was completed as part of a Scottish Executive-funded study on widening participation in $\mathrm{HE}$, and the other was funded by Integra and carried out in Ireland. The aim of outlining the findings of these case studies is to shed some light on the usefulness of the partnership approach to widening access. Whilst such an approach sounds eminently reasonable on paper, particularly the focus on de-centralisation, integrated services and grassroots development, in classic policy research terms, does the rhetoric match up with the reality? Do partnership-based out-reach programmes reach the parts other less innovative initiatives cannot?

\section{Partners in Widening Participation: Involving School, Work and Community in the Access Agenda}

According to the influential Fryer Report, one of the main methods of stimulating this demand is via 'sensitive, trusted and sustained outreach' (Fryer, 1997, p. 16), and entails 'targeted activity to raise expectations amongst children and adults, through schools, voluntary and community groups, work and trade unions.' Research in the area of out-reach access has tended to focus on partnerships with schools, work and community-based institutions. Both our case studies are community-based, but before we explore that model of partnership, it is useful to briefly describe the other two main forms of out-reach initiative.

School-HE links, both formal and informal, are becoming increasingly prominent as alternative access routes in Ireland (Osborne \& Leith, 2000) and in Scotland. These links can take many forms: mentoring/student tutoring programmes, information evenings and open days, Christmas leaver arrangements and university experience weeks. One of the more direct access UK initiatives that links schools and FE/HE institutions is the Compact. Compacts originated in the US, one of the first being the Boston Compact, which was established in 1982. This work was taken further by the National Alliance of Business, the main focus of their Compact initiative being the link between education and work (Silver, 1990). They used a 'comprehensive approach to deal with "at-risk" youth, recognising that young people need access to economic opportunity' (Silver, 1990, p. 156). Compacts basically refer to an agreement between the employer and the individual student, that if the student meets agreed goals (enhancement of personal and social qualities, key information and communication skills), there is a guarantee of further employment/training, or work placements and industrial experience. 
Compacts were introduced in Britain in 1988, and were mostly concentrated in inner city areas. Their aim was to improve the motivation, qualifications and employability of young people in local secondary schools, special schools and FE colleges' (Saunders, 1995, p. 17). Since then, another strand of Compact has developed - the School-FE/HE Compact. This model

guarantees places on HE and FE courses of the student's choice who fulfil the compact conditions.... The school guarantees the validity of Student Compact Profiles and agrees to a programme presenting the college to students through promotional materials, speakers and campus visits. (Slusarchuk, 1997, p. 158)

Another type of formal access initiative is the 'early outreach' Compacts. These generally target the 12-16 age group and aim to encourage children from disadvantaged backgrounds to overcome barriers to participation in further and higher education. Other aims of such programmes are: raising aspirations in individuals and communities; promoting the use of an enhanced curriculum; and 'combating cultural alienation' by making higher education more familiar and accessible (Slusarchuk, 1997). The Scottish Office, in its Opportunity Scotland paper (SOEID, 1998, p. 44), viewed these types of links between school and FEC/HEIs to be 'valuable in raising awareness, encouraging achievement and getting the lifelong learning message across at an early age.'

In Ireland, there is also an increased emphasis on access initiatives through partnerships between the HE sector on the one hand and schools and area-based partnerships on the other. Because participation by the highest socio-economic groups in $\mathrm{HE}$ has reached saturation point, in order to increase access the lower socio-economic groups have become the recent target for initiatives (Clancy \& Wall, 2000, p. 66). Agricultural workers, unskilled groups and children of the unemployed gain only a third of the places in HE that their proportionate size in the population would warrant. 'Policies in respect of increasing retention rates to Leaving Certificate [A-Level equivalent] and facilitating higher attainment levels at this level will be especially effective in reducing socio-economic group inequalities in access to higher education' (Clancy \& Wall, 2000, p. 69).

One interesting aspect of these school-HE links in Ireland is their embeddedness in local communities. In recent years, in the Dublin area in particular, access to $\mathrm{HE}$ initiatives have been established that link local schools to universities, receiving their impetus and energy from members of the local population, the initiative usually adopting the name of the locality as part of their moniker (e.g. Blanchardstown Initiative for Third level Education (BITE), Clondalkin Higher Education Access Programme (CHEAP)).

The promotion and support of access to third-level education in Ireland are also part of the development brief of Area Partnerships. They aim to raise individual, family and community expectations, remove barriers to participation in education and create a climate in which progression to further and third-level education becomes a realistic goal. Access programme activities in the Partnership areas typically include guidance and support to students; assistance with travel expenses, books, course fees, accommodation; local study facilities; sponsorship for participation in summer programmes such as language camps, and university visits. 


\section{European Fournal of Education}

Like school-based partnerships, work-based access to further and higher education is a relatively recent development. It is viewed as a way for those who do not have traditional qualifications to gain entry in degree programmes. It may also provide an incentive for those who had not previously considered the option of undertaking a degree. Work-based access involves the linking of academic credit to student-negotiated projects, where most of the student's learning takes place in or around the needs of the workplace. This type of negotiated learning involves three main actors: the students themselves, the employers, and tutors. This process of negotiation is 'normally formalised through a learning contract recording a work-based learning agreement. The learning contract is an important tool which is intended to give the employee an equal stake in the programme which has been agreed' (Weller, 1995, p. 207). Examples of Government funded work-based learning projects are the Learning at Work (LAW) project (Loots et al., 1998) and the Development of Employment-based Access to Learning (DEAL) project (Osborne et al., 1996).

\section{Community-based Partnerships: Linking the Local to the University}

School and work-based partnerships for access embody some similar traits and objectives, in particular their commitment to engaging with prospective students in their own environment. ${ }^{1}$ This is the clear raison d'être also of community-based partnerships. This term refers to access initiatives situated in particular areas, whether in the form of college/university outreach work, and/or in the shape of partnerships between $\mathrm{FE} / \mathrm{HE}$ institutions, voluntary sector and state organisations. The model closely associated with it is the community education model, with strong input by community and adult education groups. Community partnerships tend to diverge slightly from school and work-based approaches in that they do not usually involve links between formal institutions at their centre, instead generally involving non-formal, voluntary and non-state organisations. Their approach to out-reach therefore tends also to be of the non-formal kind.

One example is the partnership developed between Govan Community Development Training and the University of Glasgow. Govan Community Development Training is a voluntary organisation designed to develop community work skills within Govan through linked training and employment programmes. Funded by a combination of the Urban Programme and Glasgow Works, the main educational focus is the Certificate in Community Work. This was originally devised as an 'in-service route for unqualified workers to progress to a professional qualification' (Beck, 2000, p. 1). Because of the university links, however, the partnership also enabled access for such non-traditional students to higher education institutions.

Commentators such as Bird (1996, p. 55) have suggested that a critical aspect of community-based access programmes is needs assessment, an important step in building trust and fostering cooperation between local communities and institutions. 'Part of building trust and co-operation will include analysing and responding to community needs. This is a crucial step because HEIs cannot assume that what they already have to offer and how they deliver that provision will meet community needs' (Bird, 1996, p. 55).

The rest of this section outlines the main findings from the two features case studies of community-based partnership programmes, one carried out in Ireland 
and focused on an organisation called NewVision, and the other in Scotland based on the activities of a project called The Right Path. ${ }^{2}$

\section{Case Study 1: New Vision}

The Irish case study of partnership-based approaches to access is focused on a programme called New Vision. New Vision is a community training and development project working with local communities in an inner city area of Dublin. Its main objective is to reduce social exclusion through integrated local development and capacity building. There are four elements to the New Vision strategy: capacity building of local community groups and activists; engaging with service providers and partnership structures; developing a working alliance; and policy development. In terms of partnership for local development, New Vision is concerned with building a partnership between themselves and local community groups in order to develop a grassroots approach to local development and combat social exclusion.

This development began as part of a reaction to a plan by the Eastern Health Board to set up a Drug Treatment Centre which would deal with 400 addicts. A more suitable place for treatment was needed but a move was seen as futile unless preventative measures to address the problem of addiction were put in place, such as more emphasis on educational achievement. New Vision became involved when they invited local people to a meeting. This was the starting point for the development of an Integrated Area Plan, something which local people felt was a good idea as a possible remedy for low levels of formal education in the area people were anxious to be part of a project that might address these issues. Since then, two education programmes have been established - an early school leavers programme and a programme designed to foster closer collaborations between local schools.

\section{Stakeholder Perspectives}

During our research it became clear that the major success of New Vision has been capacity building. It appears that New Vision has gone some way towards bringing people together. This area in which New Vision operates, like so many, can be parochial at times, and there are rifts within and between communities that have been there for many years. Traditionally, interaction has been more or less determined by the boundaries of particular housing estates. This provided a clear barrier to development, including any hopes of raising educational attainment, and so New Vision attempted to reconfigure levels of interaction in the area. The alliance between the four areas is now considered to be better than it was. Through New Vision people from different area have met each other. People in the community believe New Vision brought expertise into the communities. As one person put it, 'the looking after accounts and the contacts they bring with them have proved to be very useful. They can point you in the right direction, for instance to a town planner or someone in the [National] Department of Social Welfare.' Others spoke of New Vision as having 'opened things up' and shown people possibilities.

Although clearly there are certain elements of the community partnership model that could be deemed a success, there were other aspects that tended to 
weaken the impact of New Vision. One of the more significant problems faced by the programme was a perceived lack of cultural sensitivity on the part of some of the partnership organisations. There is a great deal of suspicion towards outsiders based on past experience and this needs to be worked on as part of the development process. Some of the areas have considerable drug problems and associated violent gangs, and people in the areas have learnt to tread carefully. The challenge for agencies coming in from outside is to learn what is appropriate and what is not in such circumstances and be mindful that they do not have to live in the area and have to deal with the consequences. On the other hand, it does not often enter public discourse that many of the poorer communities in Ireland are held in the very tight grip of criminals and even, in some people's opinion, in the grip of political organisations and their methodologies. This is reminiscent of work undertaken elsewhere in Dundalk, on the border between Southern and Northern Ireland, where it was found that "violence is the "social glue" that maintains control in this community' (Connolly \& Fleming, 1997, p. 26).

This issue of cultural sensitivity was brought into sharp relief by a parish festival that was held and organised by New Vision. It was evident from people we spoke to that, although there were differences of opinion about the relative merits of the event, questions were raised by some about both its appropriateness for the area and of the ethos behind it - there seemed to be different understandings of what community arts meant. As one staff member admitted, 'there seems to be a difference in interests - when the community talks about the arts, it wants karaoke, while the community development programme wants painting, and the like'. There is a danger that local people perceive outsiders as acting as if they know everything. Some critical comments along these lines were made about New Vision.

There is also some evidence from interviews with people on the ground that keeping communications open, clear and up to date poses a challenge for partnership projects. It is always of central importance that agencies attempting to develop partnerships are not only aware of what each is doing but involved in the making of the decision. Any kind of competition for resources or lack of clear communication leaves the project vulnerable as a partnership. On occasion we detected a sense among people in the community that they were not consulted sufficiently.

A related issue is that of parity of esteem. It seems that there is a considerable amount of discussion in the community as to which is the 'favoured organisation' in New Vision. Some are of the opinion that some areas get more attention than others. 'One of the [areas] has got so much, and others have said why. So there's a feeling of injustice, it's supposed to be on an equal level.' Another believes it is great to see money coming into the community, but feels it is unevenly distributed among the different communities. The same person, however, cannot see the community taking eventual control of New Vision, which is the long-term plan, as it is already controlled by one of the organisations involved. These normal segmented experiences and resentments can and do get in the way of a project, but they also provide the agenda for a development project in that it is these resentments and divisions that need to be addressed as the core task of partnership building.

Finally, in a number of our interviews, comments were made about the lack of adequate numbers of staff, which is really a question of resources. According to one of the organisers we spoke to, this was the main weakness, and the 
management committee was stretched because of this. Another felt that New Vision could be doing more for the community in terms of employment:

There is no-one employed in New vision from the local community. For instance, in the summer arts course, the people who helped were from outside. Also, the Community Employment scheme is a local scheme, but there is no one in the full-time jobs from the local community. There is plenty of jobs in the Arts, they could have done it.

\section{Case Study 2: The Right Path Programme}

New Vision, as we can see, experienced a number of difficulties in attempting to achieve its objectives of developing partnerships and reducing social exclusion. And, although widening participation in education and raising attainment levels including entry to higher education, were an important part of their long-term goals, actual structures for facilitating such attainment, in the form of partnerships with higher education institutions, are only now beginning to be put in place. Developing effective partnership-based approaches to community education and development is a very difficult activity, one in which all aspects of the partnership must be developed from the ground-up, painstakingly and thoroughly.

While our Irish case-study concentrated on the partnership focus of New Vision, and was not focused on widening participation in higher education per se, it does provide a flavour of what is involved in attempts to create partnership and community-based initiatives in order to tackle poverty, social exclusion, widening access, early school leaving, low levels of educational attainment, etc. The Scottish case-study of Community-based widening participation initiatives, The Right Path Programme, is, however, directly associated with widening access to higher education in the UK, and is a useful example of UK partnership-based approaches that incorporate a community element/out-reach perspective. The Right Path Programme, which is run by a large UK-based university, is designed as a community access initiative, the main objective of which is to offer a progression route with three main transitions, moving from personal development and self-confidence building to participation in higher education. An interesting aspect of this programme is its combination of the 'in-reach' access approach (flexible entry criteria, modular provision) with the 'outreach' approach, utilising the community education approach to personal development, with heavy emphasis on guidance and support throughout the three stages.

Stage One offers a number of short courses (15-30 hours to complete); all of which are designed to help students recognise the value of the skills and experience they already have. Stage Two offers a number of return to learning courses (20 hours each) in social science, arts, maths, science and technology. The student studies mainly at home, with ongoing support and evaluation from the tutor. The third stage is aimed at building on the personal development and return to learning stages, by offering an access point into university credit bearing courses. Here, the student can choose from a range of options: studying one or more specialised short courses which can count for credit towards a degree; studying for a degree with the University; or studying with another further or higher education provider.

There are a number of interesting aspects to this Programme, but three in particular stand out as worthy of mention. The first is the partnership-based 


\section{European fournal of Education}

approach of Right Path. According to a senior member of the university, this approach is in part due to necessity as it is funded to 'work to scale.' As a result, the Programme has to be cost effective, the work being expensive and involving a considerable amount of time. According to her, there are two other aims to the partnership model: developing a tool kit that can be used as resource material by other areas; and building links with other people in the community. In this respect, they work closely with an organisation for lone parents and a women's aid organisation, particularly when it comes to attracting students to the Programme.

According to the University spokesperson, one of the problems with other educational projects of this sort has been 'bad design' with too much focus on institutional needs rather than empowerment of the students - mistakes the three-part Right Path programme is designed to avoid. She believes that, to be successful, they need to develop effective links with educational providers and organisations that could support them. The rationale behind this approach is the belief that success in community-based access initiatives depends in large part on a feeling of ownership among the communities in question. It is also based on the adult and community education philosophy of 'starting where people are at'. As the Programme Co-ordinator put it:

If you ask people if they want a degree, they will say no. 'Education is the least important thing in my life.' Ask them what their situation is and they will explain their situation. Start where they are.

The second characteristic of note is the focus not only on access mechanisms how to get people into $\mathrm{HE}$ - but also on issues of accessibility - what happens to people once they gain entry to HE. In this way, then, the aim of the Programme changes to include not only increasing access rates, but also retention levels. In this respect, curriculum development, staffing structures/training, and institutional development are all brought into the equation.

This leads to the third significant aspect of the Right Path Programme - its linking of personal development, access and academic work. The University, due to its flexible structure, is well positioned to do this kind of work, but it is paving the way for an oft-neglected partnership between community education and higher education. In access circles, a lot of work and research have been carried out on, for instance, FE-HE links, and more recently School-HE links, but relatively little has been done in the area of CE-HE links. The intention of the Right Path Programme is, in essence, to develop formal links and structures that facilitate progression between pre-access programmes (personal development; confidence building) - capacity building, if you like, access programmes (preparation for $\mathrm{HE}$; development of learning skills), and academic work. In Stage One, for instance, students can do 40-50 hours of work, with modules on 'handling stress' and 'making your experience count'. This is formalised guidance in which courses are structured to change students' stress levels. These sorts of links and routes are ones that have taken up much of the time and effort in the past of university continuing educators, and outreach and community extension workers. As the coordinator suggests, the Right Path Programme is really based on a combination of 'community development practice, adult education philosophy and higher education knowledge'. 


\section{Stakeholder Perspectives}

A number of issues arose as a result of discussions with key personnel on the Right Path Programme. The Coordinator feels the Programme offers something new in terms of education, which is based on a community development approach. $\mathrm{He}$ feels that, while mainstream education has been 'done to death' for years, community education has not performed much better, operating in an amateurish way, and existing in the 'twilight zone' of education provision. He believes that, if they are trying to 'woo' non-traditional applicants as he puts it, but not necessarily facilitating progression into higher education, community education ends up more like 'an extra-mural programme for working-class people'.

The Deputy-Director of the University feels that other programmes and institutions can learn a great deal from how the programme is structured. She feels that many institutions are 'more concerned about education rather than teaching students', and are not starting from the right point of view. Institutions need to be thinking strategically, even developing think tanks in order to plan for the future. That they were persistent enough to persuade staff to change to meet new and more varied demands means it can also happen in other institutions. She feels the current climate of access, lifelong learning and social inclusion affords the 'chance to really change things.' One of the major barriers to such change, however, and the creation of institutional structures and progression frameworks exemplified by Right Path, is the fact that if these kinds of developments are left unsupported, then it is difficult to address accessibility. This is one of the main reasons why other institutions run a number of initiatives and run into a lot of pedagogical difficulties:

They have to start building skills in students of self-assessment, to give them a lot of confidence, for them to know what to get out of the Programme. Education should have some sort of framework for this kind of progression. (University Deputy Director).

The need for creation of a new HE framework, one that incorporates effective and embedded links between community education and higher education, is reiterated by the Right Path Coordinator, who views the Scottish Executive as playing a major role in expanding the work of the University in this regard, and building on their best practice.

It is part of the remit of the University to do this kind of work ... The University has been doing rural work for years, so it's about taking their work at undergraduate level, combining it with community development practice, adult education philosophy and higher education knowledge.

One of the problems with this model and the structure of the Right Path programme is the demands it makes on tutors. To successfully negotiate the Right Path programme, tutors are required to incorporate more than one set of subject/practice skills into their teaching method. This puts extra pressure on both staff themselves and the process of finding suitably qualified staff.

Many (staff) are trained youth workers, which is a good first step. But a lot of the work was 'palliative'; it lacked an academic rigour. On the other hand 


\section{European Fournal of Education}

you could end up with performance criteria, so you need a middle course, you need authentic tutors but with rigour. In our course you need subject expertise, people with an academic background, so a combination of being able to relate to people and also academic skills is useful. There is an issue here of staff development, with different skills required for the three levels.

Another issue they face, in terms of retention and as a result, progression, is the nature of the student base targeted via Right Path. According to the Coordinator, there was quite a large drop off in the stage between expressions of interest and enrolments, particularly from the local Women's organisation. He feels this is to be expected, due to the particular circumstances of some of their students.

With [women's organisation], some of their students have been outstanding, but . . . they are not really sure if they want to be there. They may have been violently abused. There is constant disruption with kids, etc. They ... are penniless.

As part of the research, we talked to the Organiser of the women's group which provides shelter for women who have been victims of domestic abuse. She reiterates the comments made by the Right Path Coordinator and explains the difficulties these women face in accessing higher education. The key issue for them is not accessing formal education, but 'getting them socially included.' Many of the women go from living with parents to living with abusive men. According to her, some have never paid bills and do not have many basic life skills. Discussion of progression into HE does not occur at this stage, as most of the women do not believe they are capable academically. This is the purpose of Stage One, and as the Right Path Coordinator put it, Stage One is the social inclusion course for these women, rather than the later stages. The 'easy job', as he puts it, is stages Two and Three. The self-esteem and motivation need to be present before discussion of progression can take place.

According to the Organiser, the women have a 'hunch deep within them' that, with a bit of practice, they can acquire learning skills - they have an inclination they are not really 'stupid'. Many of the women, however, use phrases like 'stupid' and 'useless' to talk about themselves. According to her, once they go through Stage One, they feel they can continue. This is the major benefit of being on the Programme - 'the self-esteem it gives the women.' It also allows them to explore personal issues they may have avoided, or which may have taken them longer to confront.

From being on the course, it may take them months, but it brings up a lot of issues, and they deal with underlying problems. It speeds up the process; they see themselves as having no self-worth (Organiser).

One of the major benefits of being involved in the Programme is that the women 'leave us quicker than if they didn't' enrol on the course. After they do the course, the women 'want to do some voluntary work or something like that.' The Organiser stated that the level of pride is high after completion, and the first thing they do is 'buy a frame' for their Certificate. 
Another issue that surfaced in discussion with the Women's organisation is staffing on the Right Path Programme. The comments made by the Right Path Organiser in terms of finding suitably qualified personnel who can teach all three levels take on greater meaning in the context of delivering courses to organisations. Some of the feedback from the course is 'not as good as it could be.' This has a lot to do with the fact that delivery of such a programme proves problematic for tutors, who are not trained counsellors, and are not in a position to deal with issues that surface during class. The Women's Aid Organiser, nevertheless, argues that tutors do not necessarily need to be trained counsellors. Rather, 'they just need the right response' when issues arise. There was some discussion of in-service training to increase the quality of the Programme, in recognition of the more negative responses. At the same time, he points out that, at the heart of this kind of access initiative, are tutors 'who are prepared to give of themselves' in a classroom situation. More is required of a tutor in community-based access initiatives than confidence building and the provision of learning cultures. And for this type of training, more investment is needed to create what he considers an adequate and effective progression route. Otherwise they are 'only skimming the top of those already on the verge'.

The Programme constitutes a major attempt to provide an 'integrated' and 'partnership' based approach to widening participation and reducing social exclusion. Its adoption of a multi-agency approach falls in line with current EU thinking on social disadvantage. There is a focus on encouraging parity of esteem, where everyone has an equal footing. Links between CE and HE are fraught with difficulties, and the Programme indicates the potential of the community education sector, neglected and under-funded (after the breaking up of local authorities), in playing a central role in widening participation in HE.

Another unique characteristic of the Programme is that the University is involved in all three steps. This is unusual, particularly when it comes to dealing with the pre-access groups, those who show no interest in HE. The Programme exhibits a shift of focus from institutional needs towards a focus on the needs of students, which is refreshing in the light of comments made by others.

Attention is paid to both access and accessibility in the structure of the Right Path Programme, ensuring that entry and retention are given equal footing. The Programme is designed with this in mind, with guidance and support a crucial aspect, paralleling the formal curriculum all the way from pre-access to graduation.

The case study also raises the issue of staff development. Staff in the OU are persuaded to change to meet new demands - the question of multi-skilling staff is a significant one for such challenging work, but work that may possibly hold the key to widening participation rather than just increasing it.

\section{Local Partnerships: Identifying Elements of a Model for Best Practice}

From outlining the two case studies side-by-side, it is not too difficult to explore their similarities and where they diverge. Just as importantly, outlining them in this way provides an insight into what they may offer as a model of best practice when it comes to development a partnership-based approach to widening access to HE. Both share a common core objective, of combating social exclusion in their 
area and share a belief in providing an integrated multi-layered approach to local development. At the same time, New Vision and The Right Path utilised different approaches and understandings of what kinds of partnership would work for them. Although both focused on local community and voluntary organisations, direct links with $\mathrm{HE}$ institutions were made only with The Right Path programme.

Is there anything that each case study can learn from the approaches of the other? Do these case studies contribute to identifying a model of best practice? The first point to be made is that there is no one model of best practice for partnership approaches to widening access. There are different models, depending on the objectives and the tasks involved. Having said that, it can be argued, based on the case studies, that certain features of each partnership might benefit a general best practice model of local partnerships. We outline these under the following headings:

- Principles and values

- competence of individuals

- organisation and structure.

\section{Principles and Values}

The key issue when it comes to principles and values is the culture that exists in the partnership, particularly in regard to parity of esteem. As we saw in the discussion of the case studies, this was an important issue for the various projects, but in different ways for each. Parity of esteem in such partnerships has been indicated before as a crucial component of any integrated approach (Parkinson, 1998; Walsh et al., 1998), and the difficulties in cultivating parity, particularly in relation to the New Vision project, suggests that 'partnership' as a concept could easily become one more buzzword that disguises some possibly significant power imbalances in the process of integration. Attention should be paid to the findings of Jones \& Bird's study (2000) on public-private relations in Education Action Zones, who argue that 'partnership' is a political design for the inclusion of some interests at the same time as it accomplishes or confirms the exclusion or sidelining of others (Jones \& Bird, 2000, p. 505).

\section{Competence of Individuals}

Questions arose about staffing in both case studies. This had implications for effective delivery and integration. While aware that these are sensitive issues in any project, a clash of personalities may easily lead to problems whether at Board level, administrative level or among workers on the ground. On the other hand, it would be difficult to overestimate the importance of personal friendships as a contributor to the process of developing an integrated multi-level approach to local development. People spoke most positively about their project when it was clear that there were good personal relationships underpinning the work. This may well be as accurate an understanding of what 'local' means in local partnerships.

What should not be overlooked, however, when discussing the culture of an organisation and the competence of staff, is that these are not just questions of personality and individual effectiveness, but also of the structure and organisation of the partnership itself (Fleming \& Murphy, 2000, p. 39). 


\section{Organisation and Structure}

This final issue is of major importance in terms of building up a profile of effective models of best practice in local partnerships. Organisation and structure have implications for communication, which in turn, help to build up levels of trust and effective personal relationships. It also, more significantly, addresses the question of parity of esteem. An organisational structure that does not have a lead agency, and where decision-making is transparent and shared, may make integration easier to achieve.

In an integrated approach to local development, the local community needs to be involved, not just as clients, but also as participants in the decision-making process. It is no coincidence that New Vision and the Right Path experience difficulties when it comes to developing partnership at the local level. What they are attempting to do involves the most difficult approach to local partnership, but also probably the most effective in the long run - they are building up the capacity of the local community to take at least partial ownership of the programmes. This research underlines the importance of getting the principles and values in place; of supporting competent staff with continuing training; and of getting the organisation and structure right.

\section{Conclusion}

In an era when partnerships have been a great innovation and experiment in local development generally, one final question needs to be posed: Where to now with partnership-based approaches to widening access? One direction is clear. The emphasis from the European Union will continue to not only encourage but also mandate and require agencies to work and deliver services in an integrated manner. While the HE sector may experience more autonomy than other sectors, the twin imperative of widening access and reducing social exclusion that have risen to the top of many EU government's agendas, combined with the funding attached to performance indicators, suggest that 'partnerships' will become an increasingly significant aspect of HE delivery in the future. The experiments may not be over, but the next stage is to realise that a fragmented and territorial delivery of services serves neither clients nor providers and may indeed increase marginalisation. The task ahead is to learn from the current opportunities for experimentation and be in a stronger position to deliver services in partnership between providers and between providers and clients. The danger remains that the needs of the institution for finance and eventually survival may be met but those of the client may not (Morgan-Klein \& Murphy, 2002).

The implication of this is that the State, as a service provider, represents itself to its citizens, the service consumers, in an integrated rather than a fragmented way. This also includes involvement by citizens and communities in the design and delivery of services. This implies a totally new approach to government and the relationship between government and governed. The task is to create a structure in which both the top-down of government/state and the bottom-up of local development can coordinate their efforts, resources and tasks. If this implies a complete restructuring of local government and its remit, then the task is at least named as that. The not so hidden agenda of projects such as New Vision and the Right Path and others is a radical reform of local government. 


\section{European Fournal of Education}

\section{NOTES}

1. A more detailed and critical account of both school and work-based access programmes is provided in Murphy (2002).

2. The names of organisations have been changed to protect anonymity.

\section{REFERENCES}

Baxter, A. \& Hunt, L. (1999) Widening Participation to Higher Education in the North-East: report on HEFCE specially-funded project, Strand 2 (Newcastle, Universities for the North East).

BECK, D. (2000) The linking of work and education to enable social inclusion. Paper presented at the $30^{\text {th }}$ Annual SCUTREA Conference, 3-5 ${ }^{\text {th }}$ of July, University of Nottingham. UK: SCUTREA.

BIRD, J. (1996) Black Students and Higher Education: rhetorics and realities (Buckingham, SRHE/OU Press).

Clancy, P. \& Wall, J. (2000) Social Background of Higher Education Entrants (Dublin, Higher Education Authority).

Connolly, B. \& Fleming, T. (1997) Dundalk United and Divided: Redeemer Parish Plan for Reconciliation (NUI, Maynooth: Adult and Community Education).

Fleming, T. \& Murphy, M. (2000) Partnership for Local Development in Ireland: a study of three Integra projects (Dublin, Integra).

Forsyth, A. \& Furlong, A. (2000) Socio-Economic Disadvatantage and Access to Higher Education (Bristol, Policy Press)

FRYER, R. (1997) Creating Learning Cultures: next steps in achieving the learning age. Second report (London, National Advisory Group for Continuing Education and Lifelong Learning).

JONES, K. \& BIRD, K. (2000) Partnership as strategy: public-private relations in education action zones, British Educational Research fournal, 26, pp. 491-506.

LoOTs, C., Osborne, M. \& SEAGRAVES, L. (1998) Learning at work: work-based access to higher education, fournal of Continuing Higher Education, 46, pp. $16-30$.

MORGAN-KLEIN, B. \& MURPHY, M. (2001) Institutional strategy in widening participation, in P. TROWLER (Ed) Higher Education Policy and Institutional Change (Buckingham, SRHE/Open University Press).

MuRPHY, M. (2002) Creating new demand? The development of out-reach access initiatives in higher education, Research in Post-Compulsory Education, 7, pp. 271-288.

Murphy, M., Morgan-Klein, B., Osborne, M. \& Gallacher, J. (2002) Widening Participation in Higher Education, Report to the Scottish Executive (Stirling, Centre for Research in Lifelong Learning, Institute of Education).

NATIONAL ECONOMIC AND SOCIAL FORUM (NESF) (1997) A Framework for Partnership - Enriching Strategic Consensus through Participation (Dublin, NESF).

Osborne, M., Dockrell, R. \& ReEve, F. (1996) Access to higher education through the accreditation of work-based learning, fournal of Further and Higher Education, 20, pp. 81-96. 
OsboRne, R. \& LEITH, H. (2000) Evaluation of the Targeted Initiative on Widening Access for Young People from Socially Disadvantaged Backgrounds (Dublin, Higher Education Authority).

PARKINSON, M. (1998) Combating Social Exclusion: lessons from area-based programmes in Europe (Bristol, Policy Press).

SAUNDERS, M. (1995) The integrative principle: higher education and work-based learning in the UK, European fournal of Education, 30, pp. 203-216.

SILVER, M. (1990) The Compact project: bringing business and schools together, Educational Horizons, 68, pp. 172-178.

SKILBECK, M. (2001) The University Challenged: a review of international trends and issues with particular reference to Ireland (Dublin, Stationery Office).

SLUSARCHUK, R. (1997) From compacts to progression accords: a review, Research in Post-Compulsory Education, 2, pp. 151-164.

SOEID (1998) Opportunity Scotland: a paper on lifelong learning (Edinburgh, HMSO).

Walsh, J., Craig, S. \& MCCAfFerty, D. (1998) Local Partnerships for Social Inclusion? (Dublin, Oak Tree Press).

WELlER, G. (1995) Access through work-based learning: a learner-centred approach before its time or one that is past its 'sell-by date'?, fournal of Access Studies, 10, pp. 200-214. 
EJED3 18/1/03 02:14 PM Page 40 